\title{
The ability of laying hens to regulate phosphorus intake when offered two feeds containing different levels of phosphorus
}

\author{
G. R. Barkley, H. M. Miller and J. M. Forbes* \\ Centre for Animal Sciences, School of Biology, University of Leeds, Leeds LS2 9JT, UK \\ (Received 30 September 2003 - Revised 10 March 2004 - Accepted 29 March 2004)
}

\begin{abstract}
The ability of laying hens to adjust their intake of available P (AP) was investigated with a maize-soyabean diet fed to forty-eight individually caged birds in a $2 \times 4$ factorial experiment. From 19 to 25 weeks of age (phase 1) twenty-four birds were fed a normal-P (NP) diet $(2.2 \mathrm{~g} \mathrm{AP} / \mathrm{kg} \mathrm{DM})$ and twenty-four were fed a low-P (LP) diet ( $1.1 \mathrm{~g} \mathrm{AP} / \mathrm{kg})$. LP eggs were lighter (51 v. 54 (SEM 1.0) g; $P<0 \cdot 05)$, providing evidence that the LP diet was deficient in AP. From 25 to 28 weeks of age six hens from each phase 1 treatment were fed either the NP or LP diet alone or a choice of the LP and NP feeds or a choice of the LP feed and a phytase-supplemented (PP) feed (LP diet with 400 microbial phytase units $/ \mathrm{kg}$ ). With a choice of the NP and LP feeds, the hens fed the LP diet in phase 1 ate a smaller proportion of the LP feed (34 (SEM 12.0) \%) than the hens fed the NP diet in phase 1 (72 (SEM 12.0) \%; P<0.05), showing that P deficiency influenced subsequent selection for AP, i.e. an appetite for P was demonstrated. In those birds offered the LP and PP feeds, the presence of phytase in one of the two feeds significantly alleviated the effect of P deficiency on egg and body weights. The proportion of the LP diet chosen was not significantly affected by phase 1 treatment; it was not necessary for the hens to eat more than $50 \%$ of PP feed.
\end{abstract}

Phosphorus: Diet selection: Laying hens

Fowl (like many other animals) have evolved to eat a variety of foods and have been demonstrated to show 'nutritional wisdom', being able to balance their diets for some essential nutrients when offered a choice of foods (Forbes \& Shariatmadari, 1994). Hens eat primarily to satisfy their energy needs (Hill \& Dansky, 1954), but appetites have been shown for protein (Holcombe et al. 1976b), Ca (Hughes, 1979) and $\mathrm{P}$ (Holcombe et al. $1976 a$ ); laying hens choose to eat more of feeds with intermediate total P (TP) contents $(4.6-10 \cdot 0 \mathrm{~g} / \mathrm{kg})$ and less of those with low $(1.9 \mathrm{~g} / \mathrm{kg})$ or high $(24.3 \mathrm{~g} / \mathrm{kg})$ contents (Holcombe et al. 1976a). Diet selection methodology allows the possibility for individual laying hens to select diets to meet their own requirements and they should be able to select the level of dietary available P (AP) with which they feel most metabolically comfortable. To test the capacity to select according to requirement they should be offered a choice of feeds whereby one feed contains less than adequate AP and another equal to or more than adequate AP. Measuring the proportion of each feed eaten then gives an indication of the optimal dietary intake level.

$\mathrm{P}$ is an essential nutrient required for energy metabolism, bone development, and egg formation in the laying hen. Poultry diets normally consist of cereal grains and oil seeds that contain high concentrations of phytate. Phytate binds $\mathrm{P}$ making it relatively unavailable to simple-stomached animals as synthesis of the digestive enzyme phytase is negligible and there is insufficient endogenous phytase present in plant ingredients (Edwards, 1993). Maize and soya beans are important constituents of poultry diets but contain little endogenous phytase and the bioavailability of $\mathrm{P}$ is low, the National Research Council (1994) reporting that maize typically contains $2 \cdot 8 \mathrm{~g} \mathrm{TP} / \mathrm{kg}$ and $0.8 \mathrm{~g} \mathrm{AP} / \mathrm{kg}$ and soyabean meal 48 (extracted) $6 \cdot 2 \mathrm{~g} \mathrm{TP} / \mathrm{kg}$ and $2 \cdot 2 \mathrm{~g} \mathrm{AP} / \mathrm{kg}$. Eeckhout \& DePaepe (1994) analysed eleven samples of maize and found that the mean phytase content was 15 (SD 18) phytase units (FTU) $/ \mathrm{kg}$. The phytase content of five samples of soya bean 48 (extracted) was 8 (SD 8) FTU/kg. They concluded that this level of phytase was incapable of hydrolysing phytic acid in appreciable amounts. Microbial phytase included in the feed increases the availability of $\mathrm{P}$ from phytate (Nelson et al. 1968; Simons et al. 1990).

In the present study, diet-selection methodology was adopted with the intention of demonstrating an appetite for AP related to whether laying hens were deficient in $\mathrm{P}$ or not. The objective of phase 1 was to determine that the low-P (LP) feed was deficient in AP (deficiency being defined as a level unable to support maximal egg production). The hypothesis was that during phase 2 , hens would eat more of the normal-P (NP) or phytase-supplemented (PP) feed in preference to the LP feed, thereby demonstrating an appetite for $\mathrm{P}$ and that the $\mathrm{P}$ appetite 
would be stronger for the hens that were already $\mathrm{P}$ deficient. A secondary hypothesis was that supplemental limestone granules offered ad libitum would allow the birds to select their own $\mathrm{Ca}$ intake in relation to their AP intake.

\section{Materials and methods}

Housing, handling and euthanasia procedures were in concordance with the Ministry of Agriculture, Fisheries and Food's policies and recommendations on animal welfare. Commercially reared Lohmann Brown point-of-lay pullets ( $n$ 48) aged 19 weeks were housed in two identical environmentally controlled rooms. The monitoring period was designed to coincide with the peak rate of lay. The birds were individually caged in two-tier laying hen cages $(0.5 \mathrm{~m}$ wide $\times 0.5 \mathrm{~m}$ deep $\times 0.67 \mathrm{~m}$ tall $)$. The food containers were on the outside of the cage and holes in the front of the cage allowed the birds access to the food. The containers of water and limestone were on the inside of the cage, placed so as not to restrict access to the food. An inclined mesh floor meant that eggs rolled down and out of the front of the cage. A metal tray under the cage collected excreta.

Feed, water and supplemental limestone were available at all times. The diets were calculated to be isoenergetic $(12.1 \mathrm{MJ}$ metabolisable energy $/ \mathrm{kg})$ and isonitrogenous (17.5\% crude protein) and were formulated to contain nutrients to fulfil or exceed the National Research Council (1994) requirements of laying hens, with the exception of $\mathrm{AP}$ and the presence or absence of phytase. AP was calculated as the non-phytate $\mathrm{P}$ fraction of the diet using the non-phytate $\mathrm{P}$ values for dietary ingredients specified by the National Research Council (1994). Dietary treatments were formulated by adjusting the dicalcium phosphate and limestone inclusion levels, using cellulose to maintain the nutrient density of the diets. Microbial phytase was supplied in the form of Natuphos ${ }^{\mathrm{TM}}$, a phytase preparation from a genetically modified Aspergillus niger strain (BASF, Ludwigshafen, Germany). Three feeds were formulated; the first was the LP feed, a basal diet containing an estimated $1.1 \mathrm{~g} \mathrm{AP} / \mathrm{kg} \mathrm{DM}$. The second was the NP feed, which contained $2.2 \mathrm{~g} \mathrm{AP} / \mathrm{kg} \mathrm{DM}$, being the basal diet with the addition of dicalcium phosphate. For the third feed, the basal diet was supplemented with phytase (400 FTU/kg basal diet; PP feed), raising the AP supply to a similar level as the NP feed (Table 1) estimated using the technical information provided by BASF (1994). The feeds were mixed in $500 \mathrm{~kg}$ batches at a high-precision commercial feed mill. Limestone granules were particle size 6 (2 to $4 \mathrm{~mm}$ diameter).

At 19 weeks of age the birds were exposed to $9 \mathrm{~h}$ of light/d (08.00 to 17.00 hours) which was increased by $1 \mathrm{~h}$ per week for 4 weeks and then by $30 \mathrm{~min}$ per week until a constant lighting regimen of $16 \mathrm{~h} / \mathrm{d}(08.00$ to 24.00

Table 1. Composition of diets

\begin{tabular}{|c|c|c|c|c|c|c|}
\hline \multirow[b]{2}{*}{ Ingredient (g/kg) } & \multicolumn{6}{|c|}{ Diet } \\
\hline & Normal-P & SD & Phytase-supplemented & SD & Low-P & SD \\
\hline Maize & 600 & & 600 & & 600 & \\
\hline Hypro (48) soya & 172 & & 172 & & 172 & \\
\hline Full-fat soya & 110 & & 110 & & 110 & \\
\hline Soya oil & 10 & & 10 & & 10 & \\
\hline Mineral and vitamin premix ${ }^{*}$ & 3 & & 3 & & 3 & \\
\hline Synthetic methionine & 2 & & 2 & & 2 & \\
\hline Synthetic lysine & 1 & & 1 & & 1 & \\
\hline Salt & 2 & & 2 & & 2 & \\
\hline Sodium bicarbonate & 3 & & 3 & & 3 & \\
\hline Limestone & 90 & & 94 & & 94 & \\
\hline Dicalcium phosphate & 7 & & - & & - & \\
\hline Cellulose & - & & 3 & & 3 & \\
\hline Phytase & - & & 0.08 & & - & \\
\hline \multicolumn{7}{|l|}{ Calculated analysis } \\
\hline Metabolisable energy (MJ/kg) & $12 \cdot 1$ & & $12 \cdot 1$ & & $12 \cdot 1$ & \\
\hline Protein & 175 & & 175 & & $17 \overline{5}$ & \\
\hline Lysine & $10 \cdot 1$ & & $10 \cdot 1$ & & $10 \cdot 1$ & \\
\hline Methionine + cystine & 0.77 & & 0.77 & & 0.77 & \\
\hline $\mathrm{Ca}$ & 38 & & 38 & & 38 & \\
\hline Total P & 4.7 & & 3.4 & & 3.4 & \\
\hline Available $\mathrm{P} \dagger$ & $2 \cdot 2$ & & $1 \cdot 1$ & & $1 \cdot 1$ & \\
\hline Phytase & - & & - & & 400 & \\
\hline \multicolumn{7}{|l|}{ Analysed composition } \\
\hline Protein & 176 & 4 & 180 & 5 & 179 & 5 \\
\hline $\mathrm{Ca}$ & 36 & 2 & 34 & 1 & 38 & 2 \\
\hline Total P & 4.4 & 1 & 3.4 & 1 & 3.4 & 1 \\
\hline Phytase§ (phytase units/kg) & $<50$ & & $<50$ & & 460 & 10 \\
\hline
\end{tabular}

*Specification (per kg): vitamin A, $1.44 \mathrm{mg}$; vitamin $D_{3}, 0.03 \mathrm{mg}$; vitamin $\mathrm{E}, 1 \mathrm{~g}$; vitamin $\mathrm{B}_{1}$ (thiamin), $0.1 \mathrm{~g}$; vitamin $\mathrm{B}_{2}$ (riboflavin), $0.4 \mathrm{~g}$; vitamin $\mathrm{B}_{6}$ (pyridoxine), $0.3 \mathrm{~g}$; vitamin $\mathrm{B}_{12}, 1.5 \mathrm{mg}$; vitamin $\mathrm{K}, 0.2 \mathrm{~g}$; nicotinic acid, $2.5 \mathrm{~g}$; pantothenic acid, $0.5 \mathrm{~g}$; folic acid, $0.05 \mathrm{~g}$; Fe, $3 \mathrm{~g}$; Mn, $9 \mathrm{~g}$; Cu, $0.8 \mathrm{~g} ; \mathrm{Zn}, 6 \mathrm{~g}$; I, $0.1 \mathrm{~g}$; Se, $0.01 \mathrm{~g} ; \mathrm{Co}, 0.01 \mathrm{~g}$.

† National Research Council (1994) values used to calculate available P were $0.8 \mathrm{~g} / \mathrm{kg}$ for maize and $2.2 \mathrm{~g} / \mathrm{kg}$ for soya beans. $\ddagger$ Natuphos $^{\mathrm{TM}}$ (BASF Corporation, Ludwigshafen, Germany).

$\S$ Phytase activity analysed by photometry (BASF Corporation, Ludwigshafen, Germany). 
hours) was reached at 29 weeks of age. The temperature was a constant $21^{\circ} \mathrm{C}$.

The experiment was a $2 \times 4$ factorial design run over two phases. Phase 1 was a 6 -week period during which hens ( $n$ 48) were fed either the LP or the NP diet. Phase 2 was a 4 -week period during which the hens were fed one of the following four diets or dietary combinations: (1) NP diet, (2) LP diet, (3) choice of both LP and NP feed, or (4) choice of LP and PP feeds. The hens fed a single diet were offered two pots of the same feed as a control. Each hen had a green food container and a stonecoloured food container and the position of each container remained the same throughout the experiment. This provided a cue to enable the birds to differentiate between the feeds. The dietary treatments were allotted at random to blocks of four cages.

Individual feed intake, limestone intake, egg production, and egg weight were recorded daily. Shells were cracked, emptied, washed and dried in a $100^{\circ} \mathrm{C}$ oven for $24 \mathrm{~h}$ before weighing. Shell density $\left(\mathrm{cm}^{2}\right)$ was calculated as shell weight/surface area $\times 1000$. Surface area was calculated as egg weight ${ }^{2 / 3} \times 4.67$ as described by Tyler \& Geake (1961). Body weight was measured weekly. The left tibia was removed and analysed at the end of the experiment. Input-output balances for $\mathrm{Ca}$ and $\mathrm{P}$ were made over $7 \mathrm{~d}$ on all birds individually. In the final week of phase 2 , samples of eggs, excreta and bone were analysed for $\mathrm{Ca}$ and $\mathrm{P}$ using the method of animal feed analysis given by the Association of Official Analytical Chemists (1995). Statistical evaluation of the data was by general linear model ANOVA (Minitab, 1999). Differences between treatments were considered significant at $P<0.05$.

\section{Results}

\section{Phase 1}

Feed and limestone consumption. During phase 1 there were no significant differences in feed and limestone consumption between the dietary treatments (Table 2).

Total calcium and available phosphorus intakes. Ca and calculated AP intakes during phase 1 are shown in Table 2. Mean AP intakes were calculated to be 190 (SEM 4.0) $\mathrm{mg} / \mathrm{bird}$ per $\mathrm{d}$ for the hens fed the NP diet and 90 (SEM 4.0) $\mathrm{mg} / \mathrm{bird}$ per $\mathrm{d}$ for those fed the LP diet. There were no significant differences in $\mathrm{Ca}$ intakes with a mean intake of 5.3 (SEM 0.42) g/bird per d.

Body weights. There were no significant differences in body weight between the dietary treatments during phase 1 .
Hens weighed an average of 1470 (SEM 22) $\mathrm{g}$ at the start of the experiment and 1730 (SEM 24) g at the end of phase 1.

Egg production. There were no significant differences in egg numbers between the dietary treatments during phase 1 . The hens fed the LP diet laid lighter eggs than those fed the NP diet (52 v. 54 (SEM 0.7) g, respectively; $P<0.05)$. Egg-mass output for the hens fed the LP diet was numerically lower than that of the hens fed the NP diet in weeks 21 and 22 and this difference became significant in weeks 23 and $24(P<0 \cdot 01)$ (Fig. 1). The LP feed depressed egg-mass output compared with the NP feed and can therefore be considered to have been deficient in AP.

Feed conversion efficiency. There was a trend towards the hens fed the LP diet having a poorer feed efficiency than the hens fed the NP diet $(0 \cdot 28 v .0 .32$ (SEM 0.018) $\mathrm{g}$ $\mathrm{egg} / \mathrm{g}$ feed, respectively; $P<0 \cdot 10)$. This was significant in week $22(0.34$ and 0.45 (SEM 0.036) $\mathrm{g}$ egg/g feed for the LP and NP diets, respectively, $P<0.05$ ).

Egg characteristics. There were no significant differences in mean shell weight, proportion or density between the dietary treatments overall in phase 1 . However, in week 23 the hens fed the LP diet laid eggs with lighter and less dense shells than the hens fed the NP diet $(5 \cdot 3 v .5 .8$ (SEM $0.12) \mathrm{g} ; P<0.01$ and 79 v. $83($ SEM 1.5$) \mathrm{mg} / \mathrm{cm}^{2} ; P<0.05$, respectively).

\section{Phase 2}

For those hens fed the NP feed alone, feed consumption during phase 2 was 116 (SEM 3.5) g/d, rate of lay was 96 (SEM 1.6) $\%$ and the mean egg weight was 60.6 (SEM 0.98 ) g; egg-mass output was thus 58.6 (SEM 1.44) g/d.

Feed and limestone consumption. The feed and limestone granule intakes during phase 2 are shown in Table 3. The heading 'phase 1 effects' is included in this table to show the influence of the dietary treatment during phase 1 on feed and limestone consumption during phase 2 . There were significant differences in feed consumption in the final 2 weeks of phase 2 . The hens fed the LP diet and those offered a choice of the LP and NP feeds ate significantly less food than those fed the NP diet alone or those given a choice of the LP and PP feeds. Feed intake in phase 2 of the laying hens fed the LP diet in phase 1 is shown in Fig. 2. There was a significant interaction between the effects of phase 1 and phase 2 whereby the hens fed the LP feed in both phases ate less of the limestone granules compared with those fed the NP diet

Table 2. Feed, limestone, total phosphorus, calcium and calculated available phosphorus (AP) intakes of laying hens fed normal- or low-phosphorus diets during phase $1^{*}$

(Mean values and standard errors of the mean)

\begin{tabular}{lccccccc}
\hline Diet & $\begin{array}{c}\text { Feed intake } \\
(\mathrm{g} / \mathrm{d})\end{array}$ & $\begin{array}{c}\text { Total } \mathrm{P} \\
(\mathrm{mg} / \mathrm{d})\end{array}$ & $\begin{array}{c}\text { AP } \\
(\mathrm{mg} / \mathrm{d})\end{array}$ & $\begin{array}{c}\text { Limestone } \\
(\mathrm{g} / \mathrm{d})\end{array}$ & $\begin{array}{c}\text { Ca from feed } \\
(\mathrm{g} / \mathrm{d})\end{array}$ & $\begin{array}{c}\text { Ca from limestone } \\
(\mathrm{g} / \mathrm{d})\end{array}$ & $\begin{array}{c}\text { Total Ca } \\
(\mathrm{g} / \mathrm{d})\end{array}$ \\
\hline Normal-P & 100 & 390 & 190 & 5 & 3.2 & $2 \cdot 1$ & 5.3 \\
Low-P & 95 & 290 & 90 & 6 & 3.1 & 2.4 & 5.3 \\
SEM & $2 \cdot 8$ & 9 & 4.0 & 1.1 & 0.09 & 0.41 & 0.42 \\
$P$ & $\mathrm{NS}$ & $<0.001$ & $<0.001$ & NS & NS & NS & NS \\
\hline
\end{tabular}

${ }^{*}$ For details of diets, see Table 1. 


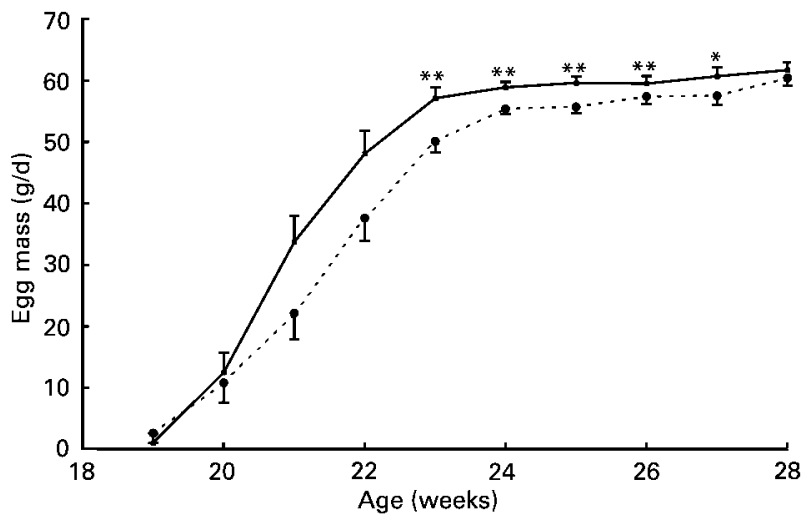

Fig. 1. Egg-mass output of laying hens fed normal- $(-)$ or low-P (---) diets during phases 1 and 2. Values are means, with standard errors of the mean represented by vertical bars. Mean values were significantly different: ${ }^{\star} P<0.05,{ }^{\star \star} P<0.01$.

in both phases (6 v. 16 (SEM 3.1) g/bird per d). Limestone intake in phase 2 of the laying hens fed the LP diet in phase 1 is shown in Fig. 3.

The proportion of each feed eaten during phase 2 is shown in Table 3. There was a significant effect in that the hens fed the LP diet during phase 1 ate less LP feed in phase 2 compared with those fed the NP feed in phase 1 (Fig. 4). There were no significant differences due to the treatments in the proportions of the two feeds eaten in phase 2. The effect of treatment in phase 1 was relatively consistent through each week of phase 2 .

Total calcium and available phosphorus intakes. A summary of the effects of dietary treatments on $\mathrm{Ca}$ and AP intakes in phase 2 is included in Table 3. The hens fed the LP feed were calculated to have consumed an average of $100 \mathrm{mg}$ AP/bird per d while those fed the NP feed ate an average of 220 (SEM 8) $\mathrm{mg}$ AP/bird per d. Total $\mathrm{Ca}$ intakes averaged 8.2 (SEM 0.85) g/bird per d.

Body weight. Mean body weights during phase 2 are shown in Table 4 . The hens offered a choice of LP and PP feeds were significantly heavier than those fed the NP feed alone or those given a choice of the LP and NP

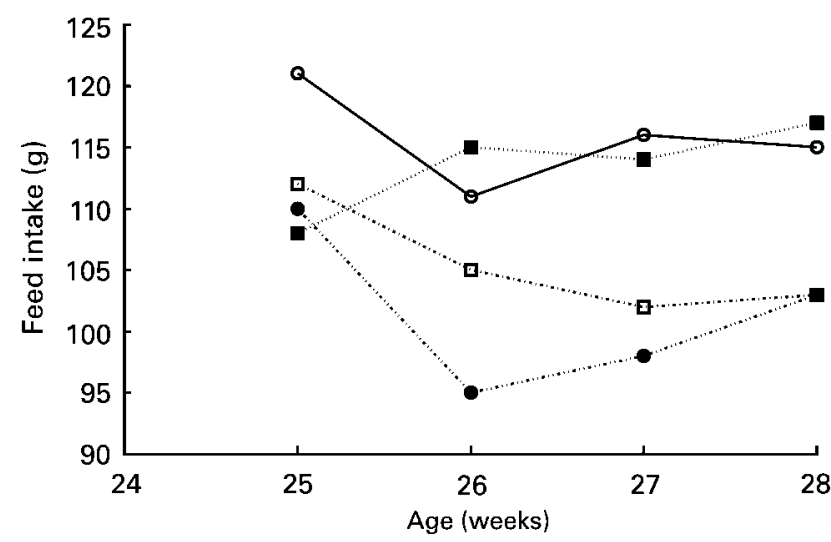

Fig. 2. Feed intake in phase 2 of laying hens fed the low-P diet in phase 1. (॰), Normal-P feed; ( $\square$ ), low-P feed; (॰), choice between normal-P and low-P feeds; ( $\mathbf{})$, choice between low-P and phytasesupplemented feeds.

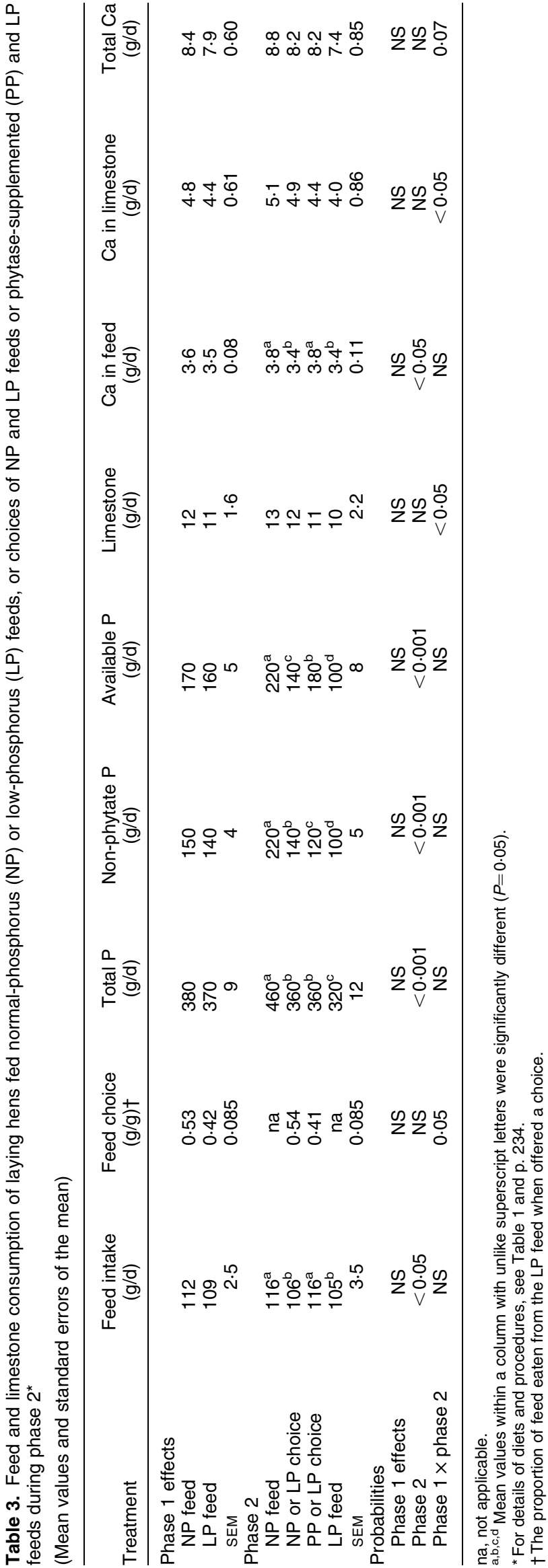




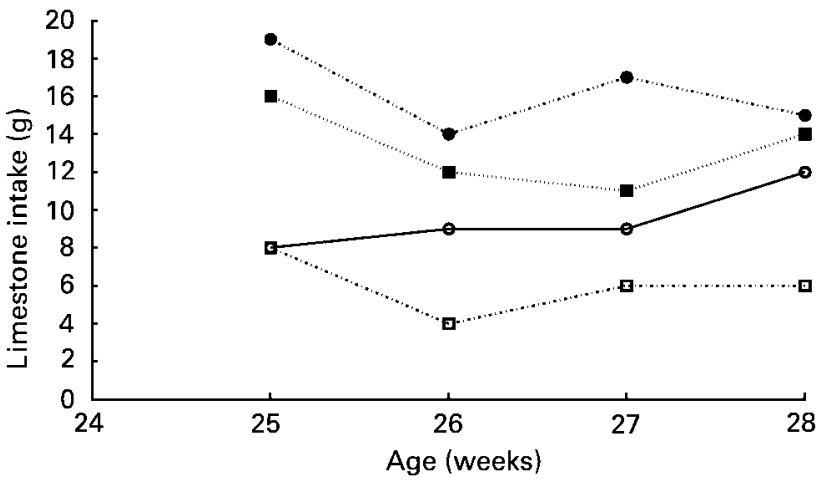

Fig. 3. Limestone intake in phase 2 of laying hens fed the low-P diet in phase 1. (०), Normal-P feed; (๑), low-P feed; (๑), choice between normal-P and low-P feeds; ( $\mathbf{(})$, choice between low-P and phytase-supplemented feeds.

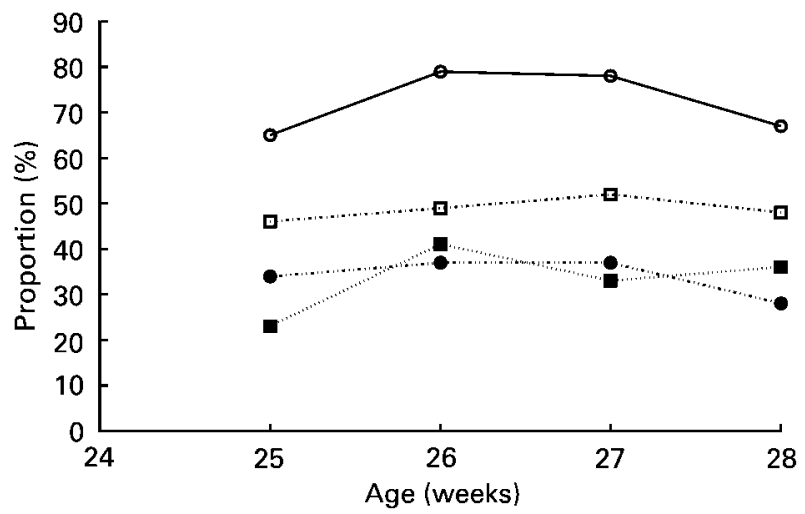

Fig. 4. Proportion of low-P feed eaten in phase 2. (०), Normal-P diet in phase 1 , choice between normal-P and low-P feeds in phase 2; ( $\square$ ), low-P diet in phase 1, choice between low-P and phytasesupplemented feeds in phase 2; $(\bullet)$, normal-P diet in phase 1 , choice between low-P and phytase-supplemented feeds in phase 2; (๘), low-P diet in phase 1 , choice between normal-P and low-P feeds in phase 2 . feeds whereas the hens fed the LP feed alone were significantly lighter.

Egg production. Production responses during phase 2 are shown in Table 4. There were no significant dietary effects on egg production. There were significant dietary treatment effects on egg weight from both phases; the hens fed the LP diet in phase 1 laid significantly lighter eggs in phase 2 compared with the hens fed the NP diet in phase 1 (59.0 v. 61.7 (SEM 0.69) g, respectively). The hens fed the LP diet in phase 2 also laid lighter eggs than those fed the NP diet (58.6 v. 60.6 (SEM 0.98) g, respectively; $P<0.05)$. The hens fed the PP feed as part of a choice diet laid the heaviest eggs (62.5 (SEM 0.98) g).

In weeks 27 and 28, the hens offered a choice of the LP and PP feeds laid significantly heavier eggs than those fed the NP feed alone whereas those offered a choice of the LP and NP feeds or fed the LP diet alone laid significantly lighter eggs. In week 28 , the hens offered a choice of the LP and PP feeds laid eggs with a mean weight of 64.2 (SEM 1.3) g. Those fed the NP diet alone laid eggs of 62.0 (SEM 1.3) $\mathrm{g}$ and those offered a choice of the LP and NP feeds or fed the LP diet alone laid eggs of 59.9 (SEM 1.3) $\mathrm{g}$.

Egg-mass output during phase 2 is included in Table 4. Egg-mass output for each week of phase 2 is shown in Fig. 5. There was a significant dietary treatment effect carried over from phase 1 on egg-mass output. The hens fed the LP diet in phase 1 had a lower egg-mass output in phase 2 than the hens fed the NP diet in phase $1(57.3 v$. 60.4 (SEM 1.02) g, respectively). In week 25 there was a highly significant effect of dietary treatments in phase 1 but the effect was not significant in subsequent weeks. In week 28, the hens offered a choice of the LP and PP feeds had a significantly higher egg-mass output than those fed the NP diet alone or those offered a choice of the LP and NP feeds whereas those fed the LP feed alone had a significantly lower egg-mass output. The hens offered a choice of the LP and PP feeds had an average egg-mass

Table 4. Production responses of laying hens fed normal-phosphorus (NP) or low-phosphorus (LP) feeds, or choices of NP and LP feeds or phytase-supplemented (PP) and LP feeds during phase $2^{*}$

(Mean values and standard errors of the mean)

\begin{tabular}{|c|c|c|c|c|c|c|c|c|c|}
\hline Treatment & $\begin{array}{c}\text { Body } \\
\text { weight }(\mathrm{g})\end{array}$ & $\begin{array}{l}\text { Production } \\
(\%)\end{array}$ & $\begin{array}{l}\text { Egg weight } \\
\text { (g) }\end{array}$ & $\begin{array}{c}\text { Egg } \\
\text { mass }(g)\end{array}$ & $\begin{array}{c}\text { Feed } \\
\text { efficiency (g:g) }\end{array}$ & $\begin{array}{c}\text { Shell } \\
\text { weight }(g)\end{array}$ & $\begin{array}{l}\text { Shell } \\
(\%)\end{array}$ & $\begin{array}{l}\text { SWUSA } \\
\left(\mathrm{mg} / \mathrm{cm}^{2}\right)\end{array}$ & $\begin{array}{c}\text { Blood } \\
\text { spots (\%) }\end{array}$ \\
\hline \multicolumn{10}{|l|}{ Phase 1 effects } \\
\hline NP feed & 1780 & 98 & $61 \cdot 7$ & $60 \cdot 4$ & 0.54 & $6 \cdot 1$ & 9.9 & 84 & 17 \\
\hline LP feed & 1740 & 96 & $59 \cdot 0$ & $57 \cdot 3$ & 0.53 & 5.8 & 9.8 & 82 & 18 \\
\hline SEM & 26 & $1 \cdot 1$ & 0.69 & 1.02 & 0.012 & 0.11 & 0.16 & 1.3 & $2 \cdot 8$ \\
\hline \multicolumn{10}{|l|}{ Phase 2} \\
\hline NP feed & $1760^{\mathrm{b}}$ & 96 & $60 \cdot 6^{\mathrm{ab}}$ & $58 \cdot 6$ & 0.51 & 5.9 & $9 \cdot 7$ & 82 & 14 \\
\hline NP or LP choice & $1740^{\mathrm{b}}$ & 96 & $59 \cdot 7^{b}$ & $58 \cdot 1$ & 0.55 & $6 \cdot 0$ & $10 \cdot 0$ & 84 & 22 \\
\hline PP or LP choice & $1840^{a}$ & 98 & $62 \cdot 5^{\mathrm{a}}$ & 61.4 & 0.53 & $6 \cdot 0$ & $9 \cdot 6$ & 81 & 18 \\
\hline LP feed & $1680^{\circ}$ & 98 & $58 \cdot 6^{\mathrm{b}}$ & $57 \cdot 3$ & 0.55 & 5.9 & $10 \cdot 2$ & 84 & 15 \\
\hline SEM & 36 & 1.6 & 0.98 & 1.44 & 0.017 & 0.15 & 0.23 & 1.9 & 4.0 \\
\hline \multicolumn{10}{|l|}{ Probabilities } \\
\hline Phase 1 effects & NS & NS & 0.01 & $<0.05$ & NS & 0.06 & NS & NS & NS \\
\hline Phase 2 & $<0.05$ & NS & 0.05 & NS & NS & NS & NS & NS & NS \\
\hline Phase $1 \times$ phase 2 & NS & NS & NS & NS & NS & NS & NS & NS & NS \\
\hline
\end{tabular}

SWUSA, shell weight per unit surface area.

a,b,c Mean values within a column with unlike superscript letters were significantly different $(P=0.05)$

${ }^{*}$ For details of diets and procedures, see Table 1 and p. 234. 


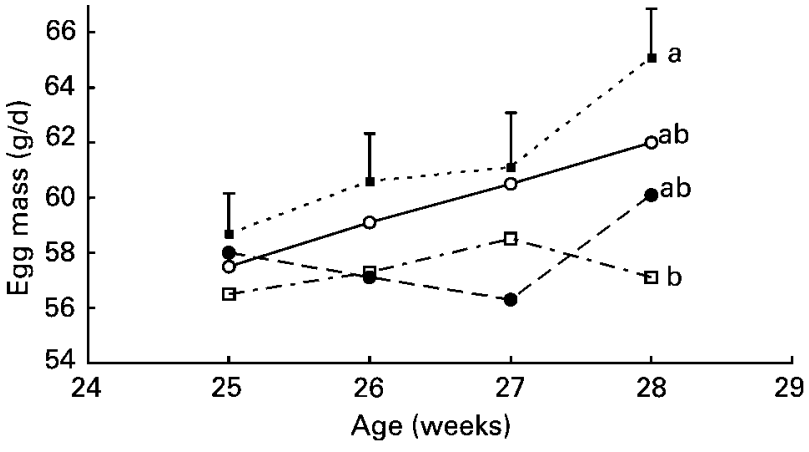

Fig. 5. Egg-mass output from laying hens during phase 2. (०), Normal-P feed; ( $\square$ ), low-P feed; $(\bullet)$, choice between normal-P and low-P feeds; ( $\mathbf{})$, choice between low-P and phytase-supplemented feeds. Values are means, with standard errors of the mean represented by vertical bars. ${ }^{a, b}$ Mean values at the same age with unlike letters were significantly different $(P=0.05)$.

output of 65.1 (SEM 1.8) g/bird per d. The hens fed the NP diet alone or given a choice of the LP and NP feeds had a mean egg-mass output of 60.1 (SEM 1.8) g/bird per $d$ and those fed the LP diet alone had an egg-mass output of 57.1 (SEM 1.8) g/bird per d.

Feed efficiency. There were no significant differences in feed efficiency between the dietary treatments (Table 4). The mean feed efficiency was 0.54 (SEM 0.017) g egg/g feed.

Egg characteristics. Eggshell characteristics and blood spots in phase 2 are included in Table 4 . There was a trend for the hens fed the LP diet during phase 1 to lay eggs with lighter shells than those fed the NP diet $(5 \cdot 8$ v. 6.1 (SEM $0 \cdot 11) \mathrm{g}$, respectively; $P<0 \cdot 10$ ). There were no significant dietary treatment effects on shell proportion or density during phase 2 during which the mean shell weight was 6.0 (SEM 0.15) $\mathrm{g}$ and the average shell density was 83 (SEM 1.9 ) $\mathrm{mg} / \mathrm{cm}^{2}$. There was a significant effect of phase 1 dietary treatments on shell weight at 26 weeks of age. There were no significant differences in the incidence of blood spots between the dietary treatments during phase $2 ; 18$ (SEM 4.0) \% of the eggs had blood spots. This was higher than would be reported commercially because all spots were counted, however small.

Calcium and phosphorus balances. The $\mathrm{Ca}$ and $\mathrm{P}$ balances are shown in Table 5. There were no significant treatment differences in $\mathrm{Ca}$ intake (from feed and limestone), $\mathrm{Ca}$ in the egg or $\mathrm{Ca}$ in the excreta. The hens fed the NP diet ate significantly more TP (460 (SEM 12) mg) than those given a choice of feeds (360 (SEM 12) mg), and the hens fed the LP diet ate significantly less (320 (SEM 12) $\mathrm{mg}$ ). There were no significant treatment differences in egg $\mathrm{P}$. There was a trend for the hens fed the NP diet to excrete more $\mathrm{P}$ than those birds fed the other dietary treatments $(310$ v. 210-230 (SEM 22) mg/bird per d, respectively; $P<0 \cdot 10$ ). There was an interaction between phases 1 and 2 on both tibia $\mathrm{Ca}$ and $\mathrm{P}$; the hens fed the NP diet in phase 1 then the LP diet in phase 2 had significantly less $\mathrm{Ca}$ and $\mathrm{P}$ in their tibias than the hens fed the other treatments $(1.0$ v. $1 \cdot 1$ (SEM 0.06) $\mathrm{g} \mathrm{Ca}$ and 450 v. 470-490 (SEM 17) $\mathrm{mg} \mathrm{P}$, respectively; $P<0 \cdot 05)$.

\section{Mortality}

Three hens died during phase 2. They had all been fed the LP diet in phase 1. One bird had been fed the NP feed, one had been fed the NP and LP feeds, and the other the LP feed in phase 2 .

\section{Discussion}

\section{Adequacy of available phosphorus in test feeds for selection methodology}

The NP feed given during phase 1 resulted in significantly higher egg-mass output, and heavier shells, than the LP feed, demonstrating that the latter provided insufficient $\mathrm{P}$ for these hens in their first few weeks of lay. Birds on this P-deficient diet would thus have entered phase 2 with depleted $\mathrm{P}$ stores and they continued to lay significantly lighter eggs throughout phase 2 . The experiment therefore provided an adequate test of the hens' ability to correct the deficiency by making the appropriate choice between feeds in phase 2 . It is also helpful, in demonstrating that a diet is deficient, to use animals with a high requirement for the nutrient in question. In this case the hens given the adequate- $\mathrm{P}$ diet were producing at the rate of 98 eggs/100 birds per d and an egg mass of over $60 \mathrm{~g} /$ $\mathrm{d}$ by the time they were in full lay at the end of phase 1 . The necessity to demonstrate that one of the feeds given in choice-feeding experiments is deficient in the nutrient in question has not been followed in some experiments (Forbes \& Kyriazakis, 1995).

\section{Ability to select available phosphorus}

A feature of the present experiment was the choice available to the hens in two of the phase 2 treatments, namely the choice of both the LP and NP feeds, or the choice of the LP and PP feeds. These were designed to test the hens' ability to self-regulate $P$ intake in line with $P$ requirement. The possession of this ability was supported by the finding that the hens fed the LP diet in phase 1, and therefore starting phase 2 in a P-deficient state, chose to eat a significantly lower proportion of the LP feed (i.e. a higher intake of AP) in phase 2 than those which had been given a P-adequate feed in phase 1 .

Phase 2 treatments did not significantly affect the birds' choice between a deficient (LP) and an adequate (NP or PP) feed. In both cases the proportion of feeds eaten was not significantly different from 0.5 which might suggest random eating. However, it might be that an optimum intake of $\mathrm{P}$ was achieved by eating approximately equal amounts of the two feeds. Just over one half $(59 \%)$ of the feed eaten by those birds offered the LP and PP feeds was the feed with phytase included at $400 \mathrm{FTU} / \mathrm{kg}$; therefore the concentration of exogenous phytase in their diet was diluted to approximately $240 \mathrm{FTU} / \mathrm{kg}$. The egg production of the hens eating the PP feed was similar to the hens eating the NP feed but the phytase treatment supported greater body weight and reduced $\mathrm{P}$ output, compared with the NP feed.

The carry-over of the effect of phase 1 treatment on the egg-mass output in phase 2 became smaller as phase 2 
Table 5. Calcium and phosphorus balance of laying hens fed normal-phosphorus (NP) or low-phosphorus (LP) feeds, or choices of NP and LP feeds or phytase-supplemented (PP) and LP feeds during phase $2^{*}$

(Mean values and standard errors of the mean)

\begin{tabular}{|c|c|c|c|c|c|c|c|c|}
\hline \multirow[b]{2}{*}{ Treatment } & \multicolumn{4}{|c|}{$\mathrm{Ca}(\mathrm{g})$} & \multicolumn{4}{|c|}{$P(\mathrm{mg})$} \\
\hline & Intake & Egg & Excreta & Tibia & Intake & Egg & Excreta & Tibia \\
\hline \multicolumn{9}{|l|}{ Phase 1 effects } \\
\hline NP feed & $8 \cdot 7$ & $2 \cdot 3$ & $6 \cdot 0$ & $1 \cdot 1$ & 380 & 110 & 240 & 490 \\
\hline LP feed & $8 \cdot 1$ & $2 \cdot 2$ & $6 \cdot 0$ & $1 \cdot 0$ & 370 & 110 & 240 & 460 \\
\hline SEM & 0.75 & 0.04 & 0.44 & 0.03 & 9 & 5 & 16 & 14 \\
\hline \multicolumn{9}{|l|}{ Phase 2} \\
\hline NP feed & $9 \cdot 2$ & $2 \cdot 3$ & 6.9 & $1 \cdot 0$ & $460^{\mathrm{a}}$ & 110 & 310 & 490 \\
\hline NP or LP choice & 8.0 & $2 \cdot 2$ & $5 \cdot 3$ & 1.1 & $360^{\mathrm{b}}$ & 120 & 210 & 490 \\
\hline PP or LP choice & $8 \cdot 6$ & $2 \cdot 3$ & $6 \cdot 4$ & 1.1 & $360^{\mathrm{b}}$ & 110 & 230 & 500 \\
\hline LP & $7 \cdot 8$ & $2 \cdot 2$ & $5 \cdot 1$ & 1.0 & $320^{c}$ & 110 & 210 & 440 \\
\hline SEM & 1.03 & 0.05 & 0.64 & 0.04 & 12 & 8 & 22 & 20 \\
\hline \multicolumn{9}{|l|}{ Probabilities } \\
\hline Phase 1 effects & NS & NS & NS & NS & NS & NS & NS & NS \\
\hline Phase 2 & NS & NS & NS & NS & $<0.001$ & NS & 0.06 & NS \\
\hline Phase $1 \times$ phase 2 & NS & NS & NS & $<0.05$ & NS & NS & NS & $<0.05$ \\
\hline
\end{tabular}

progressed (Fig. 1) whereas the effects of phase 2 treatments increased as this phase progressed. This is as expected of treatments whose effects are relatively long lived, such as dietary $\mathrm{P}$ levels, where storage of $\mathrm{P}$ in bone can buffer short-term changes in dietary supply.

The hens offered a choice between the LP and NP feeds ate less than the birds given only the NP feed. Reduction of feed intake is an important mechanism for combating $\mathrm{P}$ deprivation as bone reserves are depleted. Eating less feed reduces egg production and hence $\mathrm{P}$ demands.

Holcombe et al. (1976a) found clear evidence for diet selection according to $\mathrm{P}$ content. A difference between the present experiment and that of Holcombe et al. (1976a) was the range of dietary P. Holcombe et al. (1976a) offered choices between feeds with: (i) a low TP content $(1.9 \mathrm{~g} / \mathrm{kg})$ and a normal TP content $(4.6 \mathrm{~g} / \mathrm{kg})$; (ii) a high TP content $(10.0 \mathrm{~g} / \mathrm{kg})$ and a very high TP content $(24.3 \mathrm{~g} / \mathrm{kg})$; (iii) a low TP content $(1.9 \mathrm{~g} / \mathrm{kg})$ and very high TP content $(24.3 \mathrm{~g} / \mathrm{kg})$. The NP feed in the present experiment was similar $(4.7 \mathrm{~g} \mathrm{TP} / \mathrm{kg})$, whereas the LP feed contained $3.7 \mathrm{~g} / \mathrm{kg}$ which was approximately twice that of Holcombe et al. (1976a). Therefore, greater precision was required to choose between the feeds. Unfortunately, Holcombe et al. (1976a) did not give their dietary composition so it is not known how their low-TP diet was formulated but the LP diet in the present experiment was formulated without any $\mathrm{P}$ other than that in maize and soyabean meal. The finding that offering a choice of the LP and NP feed reduced feed consumption was similar to that of Holcombe et al. (1976a).

Possible limitations on the ability of hens to select between feeds in order to balance their nutrient requirements in the present experiment include:

(1) Lack of differentiation in the sensory properties of the two feeds. No colours or flavours were added to the feeds to assist the birds in learning the association between sensory properties and nutritional value. However, the food containers were coloured differently and their positions in the cage remained constant for each bird and this should have allowed them to learn the association (Forbes \& Kyriazakis, 1995), albeit more slowly than with more obvious sensory differentiation between the feeds themselves.

(2) The nature of the 'discomfort' induced by P deficiency. Dietary components which induce abdominal discomfort soon after ingestion are selected against once the association with sensory properties has been learned. Mild deficiencies or toxicities whose effects on metabolism have a delayed onset, and/or which do not affect abdominal receptors, are less likely to induce sensory-paired aversions (Forbes \& Rogers, 1994).

\section{Ability to select limestone}

During phase 2, the laying hens fed the LP feed throughout both phases chose to reduce their limestone intake relative to those fed the NP feed. In having to mobilise bone mineral to meet their $\mathrm{P}$ deficit, a surplus of endogenous $\mathrm{Ca}$ would have become available in the hens fed the LP diet, reducing the drive for egg-shell formation and avoiding the 'discomfort' of acute hypocalcaemia. The ability of hens to regulate their $\mathrm{Ca}$ intake in relation to their $\mathrm{P}$ intake was similar to the relationship demonstrated by Holcombe et al. (1976a) who showed that when dietary Ca was doubled from 30 to $60 \mathrm{~g} / \mathrm{kg}$ the proportion of $\mathrm{P}$ selected increased.

Another choice that may be important is that between feed and limestone. The limestone consumption was approximately $10 \%$ of feed intake. The hens showed a strong appetite for $\mathrm{Ca}$ and their $\mathrm{Ca}$ intake from limestone was higher than their $\mathrm{Ca}$ intake from feed which had been formulated to meet their $\mathrm{Ca}$ requirement.

\section{Conclusion}

In phase 1, the LP feed had deleterious effects on production, showing that this feed allowed an adequate test to be made in phase 2 as to whether the hens could 
select their diet in terms of AP when offered a choice. Hens fed the LP feed in phase 1 chose to eat less of this feed when offered a choice of the NP or LP feeds in phase 2, confirming some ability to select their diet to meet their metabolic needs. The hens also demonstrated some ability to select their limestone intake in relation to their dietary AP intake during phase 2, as the hens fed the LP feed through both phases ate less limestone than those fed the NP feed.

\section{Acknowledgements}

We thank the British Egg Marketing Board Trust for their sponsorship of a postgraduate studentship to G. R. B. and BASF for providing the microbial phytase and dietary analysis. Sue Gordon and Norman Overfield gave invaluable advice and Kenneth Humphries and Doreen Illingworth provided excellent technical assistance.

\section{References}

Association of Official Analytical Chemists (1995) Official Methods of Analysis, 16th ed. Arlington, VA: AOAC.

BASF (1994) Technical Bulletin on phosphorus nutrition of poultry. Luduigshafen, Germany: BASF Corporation.

Edwards HM Jr (1993) Dietary 1,25-dihydroxycholcalciferol supplementation increases natural phytate phosphorus utilization in chickens. J Nutr 123, 567-577.

Eeckhout W \& DePaepe M (1994) Total phosphorus, phytatephosphorus and phytase activity in plant feedstuffs. Anim Feed Sci Technol 47, 19-29.

Forbes JM \& Kyriazakis I (1995) Food preferences in farm animals: why don't they always choose wisely? Proc Nutr Soc 54, 429-440.

Forbes JM \& Rogers PJ (1994) Food selection. Nutr Abst Rev 64A, 1066-1078.

Forbes JM \& Shariatmadari FS (1994) Diet selection for protein by poultry. World's Poultry Sci J 50, 7-24.

Hill FW \& Dansky LM (1954) Studies of the energy requirements of chickens. 1. The effect of dietary energy level on growth and feed consumption. Poultry Sci 33, 112-119.

Holcombe DJ, Roland DA \& Harms RH (1976a) The ability of hens to regulate phosphorus intake when offered diets containing different levels of phosphorus. Poultry Sci 55, $308-317$.

Holcombe DJ, Roland DA \& Harms RH (1976b) The ability of hens to regulate protein intake when offered a choice of diets containing different levels of protein. Poultry Sci 55, $1731-1737$.

Hughes BO (1979) Appetites for specific nutrients. In Food Intake Regulation in Poultry, pp. 141-169 [KN Boorman and BM Freeman, editors]. Edinburgh: British Poultry Science Ltd.

Minitab (1999) Minitab for Windows. Statistical Software release 12.0. State College, PA: Minitab Inc.

National Research Council (1994) Nutrient Requirements of Poultry, 8th ed. Washington, DC: National Academy Press.

Nelson TS, Shieh TR, Wodzinski RJ \& Ware JH (1968) The availability of phytate phosphorus in soybean meal before and after treatment with a mold phytase. Poultry Sci 47, $1842-1848$.

Simons PCM, Versteegh HAJ, Jongbloed AW, Kemme PA, Slump P, Bos KD, Wolters MGE, Beudeker RF \& Vershoor GJ (1990) Improvement of phosphorus availability by microbial phytase in broilers and pigs. Br J Nutr 64, 525-540.

Tyler C \& Geake FH (1961) Studies on egg shells 15: critical appraisal of various methods of assessing shell thickness. $J$ Sci Food Agric 12, 281-293. 